\title{
The Effect of Divorce on School Performance and Behavior in Preschool Children in Greece: An Empirical Study of Teachers' Views
}

\author{
Thomas Babalis, Konstantina Tsoli, Vassilis Nikolopoulos, Panagiotis Maniatis \\ Department of Primary Education, National and Kapodistrian University of Athens, Athens, Greece \\ Email: tbabalis@primedu.uoa.gr, nadtso@primedu.uoa.gr, bnikolopoulos@minedu.gov.gr, \\ pmaniat@primedu.uoa.gr
}

Received November $1^{\text {st }}$, 2013; revised December $3^{\text {rd }}$, 2013; accepted January $2^{\text {nd }}, 2014$

\begin{abstract}
Copyright (c) 2014 Thomas Babalis et al. This is an open access article distributed under the Creative Commons Attribution License, which permits unrestricted use, distribution, and reproduction in any medium, provided the original work is properly cited. In accordance of the Creative Commons Attribution License all Copyrights () 2014 are reserved for SCIRP and the owner of the intellectual property Thomas Babalis et al. All Copyright (C) 2014 are guarded by law and by SCIRP as a guardian.
\end{abstract}

\begin{abstract}
According to the National Statistical Service of Greece, single-parent families, which emerged after divorce, in 2011 occupied an important place among other family types, endangering a large number of children to display behavioral problems and poor school performance. The purpose of the present study was to investigate the effects of divorce on preschool children. Specifically, we studied the behavior problems and academic performance of children from single-parent families compared with children from nuclear families according to teachers' views. The research sample consisted of 314 students from various urban and suburban parts of Greece, for which their 118 preschool teachers completed the "Pupil Behavior Rating Scale" (PBRS) and a questionnaire with demographic characteristics and data of themselves, their students and their students' parents. The results of the research showed statistically significant correlations between 1) the type of family and occurrence of behavioral problems and 2) the type of family and school performance of the two student groups (single parenthood-nuclear). According to the findings of the present study, it appears that the family pattern affects the emotional development and school progress of children. For this reason, bearing always in mind that each family is unique, they are of particular importance: the assurance of a structured family environment (quality relationships of the members), the regular communication with parents built upon relationships of respect and trust, and finally, the social support and assistance of competent institutions to single-parent families.
\end{abstract}

Keywords: Single-Parent Family; Nuclear Family; Parental Divorce; Behavior Problems; School Performance; Preschool Age

\section{Introduction}

During the last two decades an important literature amount has developed internationally (Amato, 2001; Babalis, 2011), in order to examine the effect of family structure on the personal and social well-being of the child. The emergence of alternative family types, such as single parenthood, raises questions as to the quality assurance in the psychosocial development of the child. According to the official definition of the Report of the European Communities for the single-parent family, this is a pattern which consists of a parent without a partner/spouse, who probably lives with his/her parents and at least one unmarried child under 18 years old dependent upon him/her (Roll, 1992). The single-parent family or lone-parent family is a new family pattern that emerged from the refusal of the marital relationship rather than the parental, and demonstrates the variety in the structure and form of the family without degrading its value. The pattern of the single-parent family ${ }^{1}$ is found in vari-

${ }^{1}$ In this study, as single-parent family is referred only the one, which emerges after the separation/divorce of parents, where the single parent lives with his/her children. That is, widowship, single motherhood and abandonment are not under scrutiny. ous types: a) the formal dissolution of marriage, separation/divorce, b) the death of a parent, c) the voluntary single paretnhood-single mother and d) the informal dissolution of marriage, after abandonment of the family by one parent. The key reasons for the evolution of the phenomenon are located into four categories of factors: a) socio-economic factors, b) demographic factors, c) factors related to family functioning and d) other individual factors (Babalis, 2011). It is characteristic that during the period 1990-2003 the rate of divorce in Greece has increased by $50 \%$, while the number of marriages was constantly reducing. In particular, according to Eurostat (2013), the number of divorces from 0.6 per thousand inhabitants that was recorded in 1990 in Greece, has risen up to 1.2 in 2009. This increase is attributed to the implementation of the legislative framework on "automatic divorce" as well as to a variety of other factors of psychosocial, economic, religious and sociological nature, since the single-parent family is a multidimensional phenomenon with social, economic and political aspects (Xatzixristou, 2009).

Children of single-parent families are being ranked in high 
risk groups not only as far as the risk of educational failure is concerned, but also regarding the possibility of social progress and acquisition of emotional wellbeing and mental resilience, i.e. psychosocial adjustment. Initially the family and then the school are invited to meet the psychosocial needs of children, which are stemming both from the social relationships with others and from the actual nature of the individual. The most common reactions of children in divorce are related to changes in behavior, such as aggression, limited interpersonal relationships, anger towards their parents, insecurity, fear of abandonment by one or both parents and feelings of guilt (Hetherington, 2002a; Wallerstein \& Lewis, 2004). Especially, in the early stages of entry into single-parenthood, behavior is characterized by isolation tendencies and outbursts of aggression. Provided that the most critical factor for the adjustment of the child is satisfied, i.e. a stable affective relationship between the child and both parents, within two years the child will have a smooth psychosocial development (Babalis, 2011). Regarding the delineation of the concept of problem behavior is a difficult issue, because of the complex and multifactorial nature of the concept of behavior, the interdisciplinary interest and the lack of valid and reliable criteria for its accurate measurement. Kauffman (2000) argues that children with behavioral problems are those that react abnormally in their environment in unsuccessful social and personal ways, which however can be improved through organized and systematic intervention. Especially for preschool age children, during which many quick changes with strong developmental pace occur, behavior problems are classified into two major categories: a) externalizing problems, such as hyperactivity, aggression, anger, disobedience, etc. and b) internalizing problems, such as inhibition, shyness, fear, anxiety, isolation, etc. (Thomas \& Guskin, 2001). Indeed, among the factors associated with the occurrence and prevalence of behavior problems are the gender and age of children. Specifically, boys and preschool age children and adolescents show higher rates of behavioral problems than girls and students in childhood upon entering the single parenthood (Manolitsis \& Tafa, 2005). According to the international literature, the exposure of children in conflict and hostile environments preceding the divorce are related with behavior and adjustment problems to a greater extent than the divorce per se (Clarke-Stewart, Vandell, McCartney, Owen, \& Booth, 2000; Wallerstein, 2003). For example, Babalis, Xanthakoy, Papa, \& Tsolou (2011) highlighted with their research the need to maintain a satisfactory communication between divorced parents as an important factor in effective child's relationship with the absent parent.

The poor prognosis or the inability to cope with problem behavior in kindergarten is characterized by a high degree of continuity in childhood and adolescence and seems to be associated with adjustment difficulties and reduced school performance, thus future school failure (McMahon, 2008; Xatzixristou \& Hopf, 1991). Adjustment difficulties in school are related to problems in interpersonal and intrapersonal behavior. And while often single parents argue that single parenthood alone is not associated with the poor school performance of their children (Pliogkou, 2011), international literature (Amato, 2001) highlights the effect of family type on general academic performance of children. At the same time, the results of some research studies (Ushie, Emeka, Ononga, \& Owolabi, 2012) do not support a causal relationship between single parenthood and school performance, thus emphasizing the inadequacy of the literature findings and indicating the importance and novelty of the present study. Among the factors that lead to decreased school performance in children who come from single-parent families are low academic expectations of lone parents (Shim, Felner, \& Shim, 2000), lack of parental involvement in their children's education (Yan \& Lin, 2005), low socio-economic status of the family (Amato \& Keith, 1991), consequent stress of the lone parent to cope with the requirements of the new family patterns (Zinn, Eitzen, \& Wells, 2008), poor quality of children's interpersonal relationships with both parents (Wallersetin \& Kelly, 1975), time phase of the traumatic experience of separation/divorce (before, during or after divorce) (Tyber, 2011) and the supporting frame-assistance provided to single-parent family from parents, siblings, friends, family, school, state and other networks (Babalis, 2013). In the Greek area the study on the effect of single parenthood on behavior and school performance of students is fragmented, as the presence of such research is limited and focuses unilaterally on some dimensions of the issue (Babalis, 2011; Kogkidou, 2006; Xatzixristou, 2009). In the light of the theoretical frame mentioned above, it can be suggested that divorce and low academic performance-behavior problems might be interrelated.

The purpose of the present research was the comparative investigation of the behavior and academic performance of preschool children from single-parent families after separation/divorce of their parents and children from nuclear families ${ }^{2}$. In particular, the behavior of children is being studied in three dimensions: school adjustment, interpersonal and intrapersonal behavior. The present study relies on the estimates of students' teachers rather than their parents, on the reports of the latter focus, almost exclusively, most international research studies (Tichovolsky, 2011), thereby creating a gap in the use of data derived from the school premises. Therefore the present study is an important approach to the topic from a new perspective, since the school and consequently teachers are considered key factors to the proper socialization of the child. And, according to the Ecological Systems Theory (Bronfenbrenner, 1994), the child develops simultaneously both in two systems, school and family. Specifically, considering that children from singleparent families are at high risk of having lower school performance and exhibiting more behavior problems compared to children from nuclear families (Wallerstein, 2003), our hypothesis is that the type of family (single-parent/nuclear) affects the behavior and the school performance of preschool children and that there exists a positive and significant relationship between the variables.

\section{Method}

\section{Participants}

The present study involved one hundred and eighteen (118) teachers with a mean of approximately eleven years of total work experience $(M=11.21, S D=8.02)$, who provided information on the family status (nuclear or single-parent family), the school performance and the behavior problems of three hundred and fourteen (314) preschool students, of which one hundred and seventy (170) were boys (percentage 54.1\%) and one hundred and forty four (144) girls (percentage 45.9\%) with a mean age of approximately five years old $(M=5.4, S D=0.8)$.

${ }^{2}$ In this study, as nuclear family is referred the one in which the child lives with both parents. 


\section{Instruments}

\section{A) Pupil Behavior Rating Scale (PBRS)}

For the measurement of behavioral problems, teachers completed for each student in our sample the "Pupil Behavior Rating Scale” (Xatzixristou \& Hopf, 1991), which consists of 11 items rated on a 5 -point Likert scale (from 1 = always until $5=$ never), where higher scores indicate fewer problems. The scale measures three dimensions: 1) School adjustment, which refers to behaviors that are associated with learning and support it (e.g. this student does not like school and is not showing interest in the courses) 2) Interpersonal behavior, which concerns students' social skills (e.g. this student quarrels with others more often than the others do and 3) Intrapersonal behavior, which is associated with psychological factors (e.g. this student gets sick or angry, or may be absent from school, when faced with a difficult subject or state).

\section{B) Questionnaire with Demographic Information and Other Data}

Simultaneously with the above scale, teachers completed a questionnaire on their demographics, which included information on gender, age, marital status, total work experience and postgraduate studies. Finally, teachers provided information about demographic characteristics and general data for their students (gender, age, and general school performance) and their families (education level, family type, nuclear or single-parent, and the degree of assistance-family support).

\section{Procedure of Data Collection}

The research was conducted the first six months of 2013 in schools of urban (Athens, Piraeus, Thessaloniki) and semiurban areas (Cyclades Islands and Rhodes island) of Greece. The questionnaires were administered by hand to the teachers, each of whom was provided with instructions regarding their completion, which took place during the working hours of the school. The completion of the questionnaires respected the codes of ethical scientific educational research and the duration of their completion was about fifteen (15) minutes.

\section{Statistical Analyses}

For the comparison of the dimensions of behavior among students coming from nuclear family and those coming from a single-parent family Student's t-tests and effect sizes of Cohen were used. The differences in the dimensions of behavior depending on the type of family were also tested with multivariate linear regression analysis taking into account the gender and age of the students. Significance levels are bilaterally and statistical significance was set at 0.05 . For the purpose of the statistical analysis of the data, the Statistical Package for Social Sciences for Windows (SPSS) (Version 19.0) was used.

\section{Results}

According to the sample characteristics, twenty one (21, or percentage $17.8 \%$ ) teachers were aged between twenty (20) to twenty nine (29) years old, forty seven (47, or percentage $39.8 \%$ ) teachers' age ranged between thirty (30) to thirty nine (39) years old, forty two (42, or percentage 35.6\%) teachers aged from forty (40) to forty nine (49) years old and finally eight (8, or percentage 6.8\%) teachers were older than fifty (50) years old. Regarding their marital status, forty teachers (40, or percentage $33.9 \%$ ) were single, sixty four $(64$, or percentage $54.2 \%$ ) were married and fourteen (14, or percentage $11.9 \%$ ) were divorced. Finally, thirty six of the total (36, or percentage $30.5 \%$ ) held a master degree, while eighty two (82, or percentage $69.5 \%$ ) did not. Regarding the students' parents who belonged to a nuclear family, one hundred and thirty five (135, or percentage $67.5 \%$ ) fathers had compulsory education level and sixty five (65, or percentage $32.5 \%$ ) fathers had higher education level. Accordingly, the education level of one hundred and thirty four (134, or percentage 67\%) mothers was compulsory and the education level of sixty six (66, or percentage 33\%) mothers was higher. The education level of the students' parents who belonged to a single-parent family was compulsory for sixty nine (69, or percentage 60.5\%) fathers and seventy (70, or percentage $61.4 \%$ ) mothers and higher for forty five (45, or percentage $39.5 \%)$ fathers and forty four (44, or percentage $38.6 \%)$ mothers.

Table 1 shows the percentages of the two types of family (nuclear/single-parent), as they are distributed to the students in our sample. Of the three hundred and fourteen (314) students, two hundred (200) belong to a nuclear family (percentage $63.7 \%$ ) and one hundred and fourteen (114) are derived from a single-parent family (percentage 36.3\%) after separation/divorce. From the latter, twenty-three (23) preschool students (percentage 20.2\%) live with their father, while the other ninety one (91) students (percentage 79.8\%) live with their mother. Fifty four (54) students (percentage $47.4 \%$ ) have recently (up to 2 years) entered single parenthood, forty six (46) students (percentage $40.4 \%$ ) live for 2 to 4 years in a single-parent family and seven (7) students (percentage 6.1\%) experience single parenthood more than 4 years.

Graph 1 shows the degree of assistance-supporting framework provided, always according to the estimates of teachers, to the single-parent family. The results showed that the teachers chose from a 5 -point Likert scale ( 1 = always and 5 = never $)$ the answers: "always" at the question which concerns the degree of assistance-supporting framework provided by parents (percentage 53\%) and siblings (percentage 41\%), "often” by relatives (percentage 35\%), "sometimes” by the state (percentage 32\%) and "never" from other people or institutions of the wider environment (percentage 50\%).

Table 2 presents the results of the comparisons of items relating to behavior problems in the two study groups (nuclear-single-parent family). Statistically significant differences $(p<0.05)$ were found in all the items of the "Pupil Behavior Rating Scale", except from the one that refers to whether "the student disobeys and questions the prestige of the teacher".

Table 3 shows the reliability or Cronbach's alpha value for the factors of the "Pupil Behavior Rating Scale" (School adjustment, Interpersonal behavior and Intrapersonal behavior), which was acceptable and greater than 0.75 . The Cronbach's alpha value of the scale was 0.864 , which indicates satisfactory internal consistency reliability. The scale has been adjusted in Greek population (Xatzixristou \& Hopf, 1991) and has showed good psychometric properties.

Table 4 presents the differences between the students of nuclear and single-parent families on the factors of the "Pupil Behavior Rating Scale". The results of multivariate analysis of variance supported the existence of statistically significant differences between students of different family types. Specifical 
Table 1.

Type of family of the students in the sample and time in single parenthood.

\begin{tabular}{cccc}
\hline & & $\mathrm{N}$ & $\%$ \\
\hline \multirow{3}{*}{ Type of family } & Nuclear & 200 & 63.7 \\
& Single-parent & 114 & 36.3 \\
& Father & 23 & 20.2 \\
& Mother & 91 & 79.8 \\
Time in single parenthood & Up to 2 years & 54 & 47.4 \\
& 2 to 4 years & 46 & 40.4 \\
& Over 4 years & 7 & 6.1 \\
\hline
\end{tabular}

\section{Assistance-Supportive Framework}

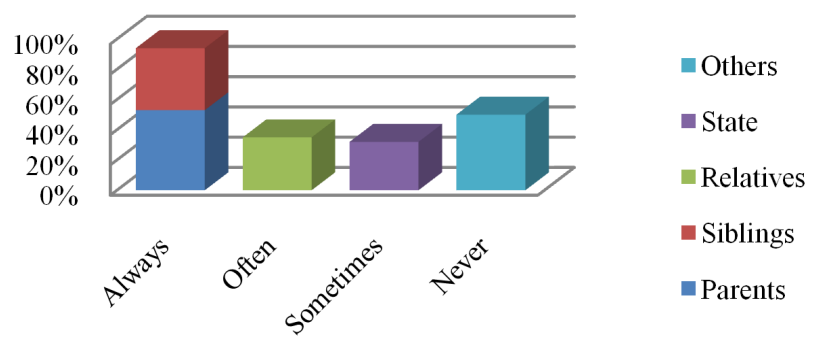

Graph 1.

To what extent and by whom there is assistance-supporting framework to the single-parent family (single parent and child).

ly, it appears that the scores of the factors School adjustment, Interpersonal behavior and Intrapersonal behavior differed significantly between groups $(p<0.001)$ with students from a single-parent family exhibiting more behavior problems. The type of the family, according to the effect sizes (Cohen's effect sizes $=$ ES) had a greater effect on Intrapersonal behavior $(\mathrm{ES}=$ $0.71)$, less in School adjustment $(\mathrm{ES}=0.43)$ and even less in Interpersonal behavior ( $\mathrm{ES}=0.39$ ).

Table 5 presents the results of multivariate linear regression analysis on the dimensions of the "Pupil Behavior Rating Scale" in relation to the gender and age of the students. Low rates were found in all three dimensions in the single-parent family compared to the nuclear, indicating that the effect of the type of family in behavioral problems of children remains significant even if we take into account the gender and age.

Table 6 presents the differences between the two study groups in the general school performance. The percentage of students who are excellent is smaller in the single-parent family compared to the nuclear, while a greater percentage of average students were found in the single parent family.

Table 7 shows that the general school performance is lower for the children of single-parent families $(p=0.020)$ compared with the children of nuclear families.

\section{Discussion}

Research data collection and analysis indicates that $63.7 \%$ of the sample belongs to a nuclear family, while $36.3 \%$ lives in a single-parent family, which emerged after the formal dissolution of marriage (separation/divorce). Indeed, in the latter case the child resides to a great extent $(79.8 \%)$ with its mother (single-mother families or mother-headed families), which is consistent with the findings of the literature (Musick \& Meier,
2010). The largest percentage of children entered recently single parenthood. Regarding the assistance-support that singleparent families are receiving, it is provided mostly by parents and siblings, sometimes by relatives, often by the state and never by other people or institutions from the wider environment.

Based on the results of the comparisons among the items that are related to behavior problems, children from single-parent families in our sample seem to have significantly more behavioral problems compared to those from a nuclear family. According to international literature (Babalis, 2013; Hetherington, 2002b), children in single-parent families are about two times more likely than those in nuclear families to have serious social, emotional or psychological problems (25\% versus $10 \%)$. An exception is the item regarding student's disobedience and question of teacher's prestige. This may be justified by the fact that, regardless of the type of family, parents encourage their children to respect their teachers and obey their instructions (Babalis, 2011).

Differences also were found in the three dimensions of the "Pupil Behavior Rating Scale” with students from a singleparent family in our sample exhibiting more behavioral problems. In particular, the type of family seems to have a greater effect on the "intrapersonal behavior" of preschool children, which means that children of single parents seem to be more isolated, shy and melancholic and get sick or angry when faced with a difficult problem. Moreover, smaller, but nevertheless statistically significant, appeared to be the effect of the type of family on the "School adjustment", which results in students who come from a single-parent family finding it difficult to follow the instructions in the lesson, having difficulties in learning, being often abstract and not liking school compared to students who belong to nuclear family.

Finally, third hierarchically, but equally significant, seems to be the effect of the type of family on the "Interpersonal behavior" with students of single-parent families quarreling often, behaving dangerously and showing immature or inappropriate behavior. These findings are convergent with others (Babalis, 2011; Babalis, Xanthakou, Papa, \& Tsolou, 2011; Xatzixristou, 2009) studying teachers' views on social adjustment and interpersonal behavior of children in Greek school, according to which the attention of children of single-parent families is easily disrupted, their behavior is often characterized as immature or inappropriate, they do not follow the instructions of a lesson easily, they appear more isolated with depression tendencies, and they exhibit more intrapersonal problems. The study as well of Babalis, Tsoli \& Tinareli (2011), which investigated the adaptation and school performance of preschool children after seperation/divorce of their parents compared to children of nuclear families in the Greek kindergarten, concluded also, among others, in the emergence of greater problems in school adjustment, interpersonal and intrapersonal behavior in the children from single-parent families. Moreover, it seems that even after taking into account children's gender and age, the effect of the type of family in behavioral problems of children remains significant, with children from single-parent families having more behavioral problems.

Finally, general school performance of students from nuclear families tends to a greater extent to "excellent" compared with students of single-parent families, who are characterized by their teachers at a greater rate as "average" students. Therefore, it seems that general school performance is lower for children 
Table 2.

Comparison of the items of behavior in the two study groups.

\begin{tabular}{|c|c|c|c|c|c|}
\hline & \multicolumn{4}{|c|}{ Type of family } & \multirow{3}{*}{ p Mann-Whitney } \\
\hline & \multicolumn{2}{|c|}{ Nuclear } & \multicolumn{2}{|c|}{ Single-parent } & \\
\hline & Mean \pm SD & $\begin{array}{l}\text { Median } \\
\text { nterq. Range) }\end{array}$ & Mean \pm SD & $\begin{array}{l}\text { Median } \\
\text { nterq. Range) }\end{array}$ & \\
\hline This student quarrels with others more often than the others do & $2.17 \pm 1.2$ & $2(1-3)$ & $2.54 \pm 1.18$ & $2(2-3)$ & 0.003 \\
\hline $\begin{array}{l}\text { This student has difficulty attending to the instruction and } \\
\text { guidance of the teacher in the classroom }\end{array}$ & $2.3 \pm 1.26$ & $2(1-3)$ & $2.76 \pm 1.14$ & $3(2-4)$ & 0.001 \\
\hline $\begin{array}{l}\text { This student has not proper behavior at school (immature or } \\
\text { inappropriate behavior for his age or for the occasion) }\end{array}$ & $2.21 \pm 1.23$ & $2(1-3)$ & $2.71 \pm 1.24$ & $3(2-4)$ & $<0.001$ \\
\hline $\begin{array}{c}\text { This student is usually shy. isolated and is not hanging } \\
\text { out with other students }\end{array}$ & $1.9 \pm 1.15$ & $1(1-3)$ & $2.38 \pm 1.09$ & $2(1-3)$ & $<0.001$ \\
\hline This student is distracted in class & $2.38 \pm 1.2$ & $2(1-3)$ & $2.81 \pm 1.15$ & $3(2-4)$ & 0.001 \\
\hline This student behaves dangerously to himself and others & $1.61 \pm 1.04$ & $1(1-2)$ & $1.99 \pm 1.03$ & $2(1-3)$ & $<0.001$ \\
\hline This student does not like school and shows no interest in the lessons & $1.78 \pm 1.09$ & $1(1-2)$ & $2.3 \pm 1.03$ & $2(1-3)$ & $<0.001$ \\
\hline This student has difficulty in learning & $2.12 \pm 1.26$ & $2(1-3)$ & $2.43 \pm 1.1$ & $2(2-3)$ & 0.005 \\
\hline $\begin{array}{l}\text { This student gets sick or angry or may be absent from school. } \\
\text { when faced with a difficult lesson or situation }\end{array}$ & $1.53 \pm 0.91$ & $1(1-2)$ & $2.06 \pm 1.06$ & $2(1-3)$ & $<0.001$ \\
\hline This student seems not to be happy. but melancholic & $1.73 \pm 1$ & $1(1-2)$ & $2.45 \pm 1.01$ & $2(2-3)$ & $<0.001$ \\
\hline This student is disobedient and questions the prestige of the teacher & $1.67 \pm 1.04$ & $1(1-2)$ & $1.86 \pm 1.18$ & $1(1-2)$ & 0.135 \\
\hline
\end{tabular}

Table 3.

Means (M), Standard Deviations (SD) of students and reliability indices (Cronbach’s a) in the "Pupil Behavior Rating Scale" factors.

\begin{tabular}{ccccc}
\hline & Minimum Value & Maximum Valus & Mean \pm SD & Cronbach’s a \\
\hline School adjustment & 4.00 & 20.00 & $14.81 \pm 4.09$ & 0.89 \\
Interpersonal behavior & 4.00 & 20.00 & $15.82 \pm 3.85$ & 0.85 \\
Intrapersonal behavior & 3.00 & 15.00 & $12.22 \pm 2.62$ & 0.75 \\
\hline
\end{tabular}

Table 4.

Mean (M), Standard Deviations (SD) of students in single-parent and nuclear families in the "Pupil Behavior Rating Scale” factors.

\begin{tabular}{cccccc}
\hline & \multicolumn{3}{c}{ Type of family } & & \\
\cline { 2 - 3 } & Nuclear & Single-parent & & \multirow{2}{*}{ Cohen's d $^{*}$} \\
\cline { 2 - 3 } & Mean \pm SD & Mean \pm SD & & \\
\hline School adjustment & $15.44 \pm 4.22$ & $13.7 \pm 3.6$ & $<\mathbf{0 . 0 0 1}$ & 0.43 \\
Interpersonal behavior & $16.35 \pm 3.82$ & $14.88 \pm 3.72$ & $\mathbf{0 . 0 0 1}$ & 0.39 \\
Intrapersonal behavior & $12.85 \pm 2.52$ & $11.1 \pm 2.41$ & $<\mathbf{0 . 0 0 1}$ & 0.71 \\
\hline
\end{tabular}

"a "small" effect size is 0.20 , a "medium" effect size is 0.50 , and a "large" effect size is 0.80 .

Table 5.

Results of linear regression models for the effect of the type of family on the dimensions of behavior problems taking into account the gender and age of the child.

\begin{tabular}{|c|c|c|c|c|}
\hline School adjustment & & $\beta$ & SE & $p$ \\
\hline \multirow[t]{2}{*}{ Type of family } & Nuclear & $0.00^{*}$ & & \\
\hline & Single-parent & -1.71 & 0.48 & $<0.001$ \\
\hline \multicolumn{5}{|l|}{ Interpersonal behavior } \\
\hline \multirow[t]{2}{*}{ Type of family } & Nuclear & $0.00^{*}$ & & \\
\hline & Single-parent & -1.32 & 0.45 & 0.003 \\
\hline \multicolumn{5}{|l|}{ Intrapersonal behavior } \\
\hline \multirow[t]{2}{*}{ Type of family } & Nuclear & $0.00^{*}$ & & \\
\hline & Single-parent & -1.79 & 0.30 & $<0.001$ \\
\hline
\end{tabular}


Comparison of general school performance in both study groups.

\begin{tabular}{|c|c|c|c|c|c|c|}
\hline & & \multicolumn{4}{|c|}{ Type of family } & \multirow{3}{*}{$p$ Pearson's $\mathrm{x} 2$ test } \\
\hline & & \multicolumn{2}{|c|}{ Nuclear } & \multicolumn{2}{|c|}{ Single-parent } & \\
\hline & & $\mathrm{N}$ & $\%$ & $\mathrm{~N}$ & $\%$ & \\
\hline \multirow{4}{*}{ General school performance } & Week & 29 & 15.3 & 13 & 11.7 & \multirow{4}{*}{0.002} \\
\hline & Moderate & 38 & 20.0 & 41 & 36.9 & \\
\hline & Good & 71 & 37.4 & 42 & 37.8 & \\
\hline & Excellent & 52 & 27.4 & 15 & 13.5 & \\
\hline
\end{tabular}

Table 7.

Mean (M), Standard Deviations (SD) and Median (Interquartile range) of the general school performance in the two study groups.

\begin{tabular}{lccccc}
\hline & \multicolumn{5}{c}{ Type of family } \\
\cline { 2 - 6 } & \multicolumn{4}{c}{ Nuclear } & \multicolumn{2}{c}{ Single-parent } & Mean \pm SD & Median (Interq. Range) & Mean \pm SD & Median (Interq. Range) & 0.020 \\
General school performance & $2.77 \pm 1.02$ & $3.00(2.00-4.00)$ & $2.53 \pm 0.87$ & $3.00(2.00-3.00)$ & \\
\hline
\end{tabular}

of single parents than children of nuclear families in our sample. This gap between the type of family and academic achievement between the two groups of students is also supported by the literature (Uwaifo, 2012). The time that the students in our sample live in a single-parent family is short, which certainly affects and justifies to an extent the results of the research concerning their behavior and academic performance.

Schools ought to show understanding and sensitivity, provide assistance in cases of addressing difficulties and, through maintaining an objective attitude, develop policies to support single-parent families. Initially, it is necessary to create a learning environment that will be characterized by a specific structure and stable organization, providing equal learning opportunities to all students and aiming to the enhancement of personal and social development of all members in a positive school climate. Towards this direction, proper education and training of teachers will contribute the most, through seminars on issues related to school psychology and mainly to normal school adjustment of students from alternative types of family life. The universal based programs may reduce any conscious or unconscious biases held by teachers against children from single-parent families and reinforce their leadership and advisory role.

The lifelong learning and education on behavioral issues to groups of children who exhibit striking problems, of course should not be limited only to teachers, but need to be extended to parents of the school, in order to strengthen this important dipole of communication and collaboration aiming at the wellbeing of the child (Epstein, 1995; Koutrouba, Antonopoulou, \& Babalis, 2010). The growing sense of love and security and the compliance with stable limits on the behavior of both parents are auxiliary agents with positive results (Babalis, 2011). Of major importance is the collaboration of the school with relevant local government agencies in providing appropriate support to lone-parent families. Often indeed, increased behavioral problems are associated with low socioeconomic status, social exclusion and poverty, the levels of which, according to research data (Bougioukos, 2011) are lower in single-parent households compared to other types of family. Therefore, social support is necessary in order to improve and promote the mental and physical health of these children.

The present study has a number of limitations. Firstly, the conclusions were based on the views of teachers, without taking into consideration the views of children and their parents. Moreover, additional important factors, such as the socio-economic status of the family or the degree of parental involvement in children's education were not taken into account. Lastly, instead of or in combination with the "Pupil Behavior Rating Scale", which is a self-report scale, the study could have taken advantage of the data derived from an interview as well.

In future study, researchers should consider exploring, additionally to the teachers, the views of children and their parents by using self-report questionnaires or tests and 360 degree questionnaires simultaneously. Also, emphasis should be placed on the impact of further factors related to divorce, e.g. the duration of single parenthood, the quality of interpersonal relationships with both parents or social and economic status of the family.

\section{REFERENCES}

Amato, P. R. (2001). Children of divorce in the 1990s: An update of the Amato and Keith (1991) meta-analysis. Journal of Family Psychology, 15, 355-370. http://dx.doi.org/10.1037/0893-3200.15.3.355

Amato, P. R., \& Keith, B. (1991). Parental divorce and adult well-being: A meta-analysis. Journal of Marriage and the Family, 53, 43-58. http://dx.doi.org/10.2307/353132

Babalis, Th. (2011). Children of single-parent families: Helping in school adaptation. Athens: Diadrassi (in Greek).

Babalis, Th. (2013). Dimensions of social exclusion and poverty among single-parent families in Greece. In D. Daskalakis (Eds.), The Social Sciences and the Current Crisis (pp. 459-489). Athens: Papazisi (in greek).

Babalis, Th., Tsoli, K., \& Tsinarelis, G. (2011). Parents' divorce and adjustment of preschool children in kindergarten. Proceedings of the European Conference OMEP 2011 on Perspectives on Creativity and Learning in Early Childhood. Cyprus (in Greek).

Babalis, Th., Xanthakou, Y., Papa, C., \& Tsolou, O. (2011). Preschool age children, divorce and adjustment: A case study in Greek kindergarten. Electronic Journal of Research in Educational Psychology, 9, 1403-1426.

Bougioukos, G. (2011). The effects of economic crisis on children and their rights. In D. Daskalakis, \& M. Gkivalos (Eds.), Childhood and Children's Rights (p. 130). Athens (in Greek).

Bronfenbrenner, U. (1994). Ecological models of human development. In International Encyclopedia of Education (Vol. 3, 2nd ed.). Oxford: Elsevier. 
Clarke-Stewart, K. A., Vandell, D., McCartney, K., Owen, M., \& Booth, C. (2000). Effects of parental separation and divorce on very young children. Journal of Family Psychology, 14, 304-326.

http://dx.doi.org/10.1037/0893-3200.14.2.304

Epstein, J. L. (1995). School-Family-Community Partnerships: Caring for the children we share. Phi Delta Kappan, 76, 701-712.

Eurostat (2013). Social Europe. EU employment and social situation. Quarterly review. Special supplement on demographic trends. Luxembourg: Publications office of the European Union. http://epp.eurostat.ec.europa.eu/cache/ITY_OFFPUB/KE-BH-13-0S 2/EN/KE-H-13-0S2-EN.PDF

Hetherington, E. M. (2002a). Child psychology: A contemporary viewpoint (updated 5th edition revised by R. D. Parke \& V. O. Locke). New York: McGraw-Hill.

Hetherington, E. M. (2002b). For better or for worse: Divorce reconsidered. New York: W.W. Norton and Company.

Kauffmann, J. M. (2000). Characteristics of emotional and behavioral disorders of children and youth (7th ed.). Columbus: Merill Prentice Hall.

Kogkidou, D. (2006). Children, parenting and society: What can we learn from single parents? In M. Malikiosi-Loizou, D. SidiropoulouDimakou, \& G. Kleftara (Eds.), Counseling Psychology in Women (pp. 136-167). Athens: Ellinika Grammata (in Greek).

Koutrouba, K., Antonopoulou, K., \& Babalis, Th. (2010). Parental involvement in secondary education schools: The views of parents in Greece. Educational Studies, 33, 1465-3200.

Manolitsis, G., \& Tafa, E. (2005). Checklist for detecting behavior problems in preschool age. Psychology, 12, 153-178 (in Greek).

McMahon R. J. (2008). Parent training interventions for preschool-age children. In R. E. Tremblay, R. G. Barr, \& R. DeV. Peters (Eds.), Encyclopedia on Early Childhood Development (pp. 1-8). Montreal, Quebec: Centre of Excellence for Early Childhood Development. http://www.excellence-earlychildhood.ca/documents/McMahonRJA NGxp.pdf

Musick, K., \& Meier, A. (2010). Are both parents always better than one? Parental conflict and young adult well-being. Los Angeles: California Center for Population Research.

http://papers.ccpr.ucla.edu/papers/PWP-CCPR-2008-022/PWP-CCP R-2008-022.pdf

Pliogkou, V. (2011). Which factors affect the education of children of single-parent families? From the perspective of lone parents. In proceedings of the $1^{\text {st }}$ Panhellenic Conference of single-parent families on Single-parent families in modern society (pp. 72-92). Alexandroupoli: Association of single parents in the prefecture of Evros "Support” (in Greek).
Roll, J. (1992). Lone parent families in the European Community. The 1992 report to the European Commission. Brussels: Commission of the European Communities.

Shim, M. K., Felner, R. D., \& Shim, E. (2000). The effects of family structures on academic achievement. Proceedings of the annual meeting of the American Educational Research Association, New Orleans, LA.

Thomas, J. M., \& Guskin, K. A. (2001). Disruptive behavior in young children: What does it mean? Journal of the American Academy of Child and Adolescent Psychiatry, 40, 44-51. http://dx.doi.org/10.1097/00004583-200101000-00015

Tichovolsky, M. H. (2011). Parenting and parent predictors of changes in child behavior problems. Thesis. Massachusetts: University of Massachusetts Amherst, Department of Clinical Psychology.

Tyber, E. (2011). Children after divorce. How you can help your children adapt to the new situation. Athens: Modern times (in Greek).

Ushie, M. A., Emeka, J. O., Ononga, G. I., \& Owolabi, E. O. (2012). Influence of family structure on students' academic performance in Agege local government area, Lagos state, Nigeria. European Journal of Educational Studies, 4, 177-187.

Uwaifo, V. O. (2012). The effects of family structure on the academic performance of Nigerian university students. Global Journal of $\mathrm{Hu}$ man Social Science, 12, 53-56.

Wallerstein, J. S. (2003). What about the kids? Raising your children before, during and after divorce. New York: Hyperion Press.

Wallerstein, J. S., \& Kelly, J. B. (1975). The effects of parental divorce: Experiences of the preschool child. Journal of the American Academy of Child Psychiatry, 14, 600-616. http://dx.doi.org/10.1016/S0002-7138(09)61460-6

Wallerstein, J. S., \& Lewis, J. M. (2004). The unexpected legacy of divorce. Report of a 25-year study. Psychoanalytic Psychology, 21, 353-370. http://dx.doi.org/10.1037/0736-9735.21.3.353

Xatzixristou, X. (2009). The separation of the parents, divorce and the children. The adjustment of children in binuclear family and school. Athens: Ellinika Grammata (in Greek).

Xatzixristou, X., \& Hopf, D. (1991). Behavior problems and school performance of students in primary and secondary education according to teachers' estimates. Educational Review, 14-15, 107-143 (in Greek).

Yan, W., \& Lin, Q. (2005). Parental involvement and mathematics achievement: Contrast across racial and ethnic groups. The Journal of Educational Research, 99, 116-127. http://dx.doi.org/10.3200/JOER.99.2.116

Zinn, B. M., Eitzen, S. D., \& Wells, B. (2008). Diversity in families (8th ed.). Boston: Allyn and Bacon. 